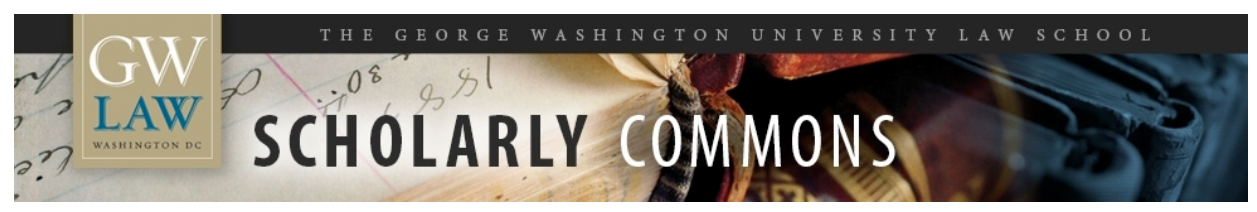

\title{
Behavioral Biology, the Rational Actor Model, and the New Feminist Agenda
}

Naomi R. Cahn

George Washington University Law School, ncahn@law.gwu.edu

June Carborne

Follow this and additional works at: https://scholarship.law.gwu.edu/faculty_publications

Part of the Law Commons

\section{Recommended Citation}

Naomi Cahn \& June Carbone, Behavioral Biology, the Rational Actor Model, and the New Feminist Agenda, Res. L. \& Econ. (2007).

This Article is brought to you for free and open access by the Faculty Scholarship at Scholarly Commons. It has been accepted for inclusion in GW Law Faculty Publications \& Other Works by an authorized administrator of Scholarly Commons. For more information, please contact spagel@law.gwu.edu. 
_ RESEARCH in LAW AND ECONOMICS _ (forthcoming 2007)

\title{
BEHAVIORAL BIOLOGY, THE RATIONAL ACTOR MODEL, AND THE NEW FEMINIST AGENDA
}

\author{
June Carbone and Naomi Cahn ${ }^{1}$
}

Law and the social sciences are on the brink of a paradigm shift. For the last half century, imperial economics and the rational actor model have dominated academic discourse. The model's simplifying assumptions that bracketed distributions of wealth and entitlements, assumed that preferences were exogenously determined, and maintained that individuals acted to maximize their own self interest provided a powerful research tool. While economists have always recognized that the model did not accurately describe human motivation and while subsequent models selectively relaxed the original assumptions, the basic model generated predictions about the potential impact of proposed policies, and served to explain the limitations of command-control economics as Communism and socialism appeared to run their course. With the "fall of the wall," Fukuyama's celebration of "The End of History," and globalization, the final triumph of decentralization, autonomy and markets appeared at hand.

Rather than assure the continued dominance of rational actor methodology, however, the very success of deregulation and decentralization is insuring its demise. The most interesting issues of the day, which once focused on the structure of government, are today more focused on the creation of markets and the role of culture.

\footnotetext{
${ }^{1}$ The authors thank the participants at the Seattle conference [name] and at Martha Fineman's Uncomfortable Conversation on Sociobiology, Evolutionary Psychology, and Feminist Legal Theory the Mid-west Law and Economics Association, Jack Kirkwood and Kathy Baker for their comments, and Reeruparna Dutta for her research assistance.
} 
How do societies manage the transition to freer markets and decentralized decisionmaking? What is the minimum infrastructure necessary for a well-functioning society? Why do some cultures, even within the same society, prosper more readily than others? And perhaps most critically, how do societies instill habits of honesty and trustworthiness that even Richard Posner sees as enhancing the efficiency of markets? (Posner 1998)

In addressing these issues, more complex models of human motivation are critical. Economics itself, led by the insights that have come from game theory, is increasingly focused on examination of trust, altruism, reciprocity and empathy. (Goodenough 2007) Behavioral economics, which has been defined as "the combination of psychology and economics that investigates what happens in markets in which some of the agents display human limitations and complications," attempts to systematically address the limitations of rational actor assumptions. Jolls, Sunstein and Thaler (1998) observe that the "unifying idea in our analysis is that behavioral economics allows us to model and predict behavior relevant to law with the tools of traditional economic analysis, but with more accurate assumptions about human behavior, and more accurate predictions and prescriptions about law." As the number of exceptions to the assumptions of rationality have multiplied, and as the issues of the hour make the exceptions as, if not more, important than the rules, a multitude of disciplines have joined the behaviorists in proposed alternative theories of human motivation (Prentice, 2003). ${ }^{2}$

We believe that these efforts cumulatively are on the brink of dethroning the rational actor model altogether for a more robust theory of human motivation. We will

\footnotetext{
${ }^{2}$ See, e.g., economist Robert Prentice's observations that: "The premise of a rational actor that is fundamental to much law and economics theory is simply wrong, meaning that this scholarship often generates explanations that are unpersuasive, conclusions that are unverifiable, predictions that are unreliable, and policy prescriptions that are unsatisfying."
} 
argue that the most likely source for a new comprehensive theory will come from the integration of behavioral economics with behavioral biology, and that the success of this project in turn depends on the integration of the insights that come from evolutionary analysis, genetics and neuroscience. Other work, and particularly Owen Jones' careful and comprehensive scholarship (see Jones and Goldsmith, 2005), lays out the promise of behavioral biology for law. In this piece, however, we will place these developments within biology and economics in a framework that shifts the focus of legal discussion from the limitations of the regulatory state to the creation of institutions, private and public, that effectively serve to instill norms and coordinate human activity. In the process, we will argue that the new paradigm and the research agenda that accompanies it will be greatly enriched by a reconsideration of the importance of feminism.

"Homo economicus" (see Prentice, 2003), ${ }^{3}$ that is, the simplified rational actor, maximizes utility by focusing on a relatively narrow definition of self-interest, one largely defined in terms of material well-being (see Posner, 1980 and Kronman, 1980). ${ }^{4}$ If there is to be an alternative paradigm, it is likely to come from behavioral biology, which starts with Darwin's assumption that any adaptation that provides a better chance of replication is likely to perpetuate itself (Dawkins 2006 and Jones 1997). This analysis provides information about the differing motivations that explain behavior which go beyond assumptions concerning self-interest. Although the foundational concept of the "selfish gene" might appear to support the rational actor, evolutionary theory has explored the impact of culture on both the genetic and behavioral levels as well as the short- and long-term implications of acting "selfishly" (Dawkins, 2006). Indeed,

\footnotetext{
${ }^{3}$ Also known as "Chicago Man"

${ }^{4}$ Debate between Tony Kronman and Richard Posner in which Posner argues that wealth maximization was an acceptable substitute utility maximization because of the difficulties of determining utility.
} 
evolutionary analysis addressed the issues that arise from altruism decades before behavioral economics, incorporating William Hamilton's idea of "inclusive fitness" into basic theories of natural selection in the sixties (Hamilton, 1964) ${ }^{5}$, and Robert Trivers' (1972) theories of "reciprocal altruism" and parental investment in the seventies. ${ }^{6}$ Tooby and Cosmides (1992) extended evolutionary analysis not just to physical innovations or observable behavior, but to the operation of the mind itself, finding that the complexity of the mind is as based in natural selection as is the complexity of the physical body. ${ }^{7}$

Moreover, while the rational actor model treats human motivation as a black box, and looks for "revealed preferences" only through the physical manifestations of behavior, developments in neuroscience make possible a more sophisticated understanding of how individuals reach decisions (Jones and Goldsmith, 2005). Contemplating the use of neuroimaging techniques that distinguish between dilemmas that engage the portion of the brain associated with reason versus those engaging the areas that mediate emotion, Jedidiah Purdy (forthcoming) observes that: "Like alchemists who dreamed of finding an elixir of life and mystics who labored to see the face of God, investigators now speak of 'seeing utility.'" Even the rational actor model becomes a different beast with the ability to define utility with greater precision.

\footnotetext{
${ }^{5}$ Theorizes that "natural selection favors characteristics that cause an organism's genes to be passed on, regardless of whether the organism produces offspring directly.") An uncle who contributes to a niece's well-being, for example, helps promote the survival of a child who will pass on a significant portion of his own genes. See also Jones and Goldsmith (2005) at 430-31 on kin selection.

${ }^{6}$ Trivers predicted that, for all species, the sex that invests more in children will be more discriminating in the selection of mates while the sex that invests less will be more competitive for sexual access to the high investing sex. He also predicted a conflict of interest between parents and children, with parents sometimes, for example, weaning an infant at a less than optimal time for the infant in order to bear additional children. Also see Trivers (1974).

${ }^{7}$ They observed that: "Darwin took [a] ... radical step toward uniting the mental and physical worlds, by showing how the mental world - whatever it might be composed of - arguably owed its complex organization to the same process of natural selection that explained the physical organization of living things. Psychology became united with the biological and hence evolutionary sciences."
} 
Finally, advances in genetics have themselves produced a greater appreciation of the role of culture in shaping human preferences. Jones and Goldsmith (2005) report that:

... human behavior, it turns out, is even more complex and more interesting than commonly supposed. ... [G]enes do not alone determine behavior, for experience and culture exert important and strong influences. Yet brains are not blank slates on which culture can inscribe anything with equal ease, for genes affect learning and contribute to cultural patterns common to the species. All human behavior reflects the intersection of genes, environments, developmental history, and the evolutionary processes that built the brain to function in the ways it does. This means that the human organism is neither genetically determined nor environmentally determined, but rather possesses multiple potentials that arise through successive interactions of genes and environments.

For example, studies that establish genetic predisposition to depression nonetheless show that depression may not occur absence a major triggering event (Caspi et. al., 2003).

Conditions in utero that in turn reflect the mother's status and well-being, and cultural transmission that primes brain pathways also affect the expression of genetically transmitted traits. In the new world of biology, nature and nurture are inextricably intertwined (Ridley, 2003).

Taken together, these and other developments in behavioral biology offer a comprehensive new approach to human behavior and motivation. While the new paradigm has not yet completely emerged, we believe that the new, biologically-based, methodologies will offer a foundation for a progressive agenda that focuses more directly on how the interaction of humans influences the well-being of societies. This new paradigm will offers the potential of a fuller, richer, more complex understanding of why individuals actually behave in ways that not only advance narrow self-interest but also sacrifice self-interest in ways that advance the greater good. It must account not just 
for preference manifestation, but also for preference shaping. To realize the promise of this new paradigm, however, will require reconsideration of the role of gender.

Evolutionary analysis, if it has any coherence, does so because of its focus on reproduction. Reproduction necessarily involves the combination of male and female, and behavioral biology often begins with differences in gender strategies, as Trivers' theory of parental investment suggests. Add neuroscience. If we peer into people's brains, are we likely to discover that gender matters, that there is a correlation between these different gendered evolutionary strategies, different brain development, and different contemporary behaviors. Moreover, a greater understanding of genetics is likely to produce not only more information about sex-linked characteristics, but greater study of what determines conditions in the mother's uterus that prime fetal development, and the role of maternal bonding and transmission of values that activates or suppresses genetic predisposition. It is impossible to discuss biology without considering gender.

Of course, addressing gender explicitly raises fears that male and female will be defined in terms of essentialist qualities, and that the historic discrimination against women in accordance with the gender stereotypes of the day will be reinforced. While we believe that the new biology distinguishes between differences in observed preferences and differences in fundamental capacity, we also believe that the multiple risks that come from stereotyping are real. While we cannot let the threat of stereotyping affect our acquisition of knowledge, we must acknowledge the threat and confront it.

In this paper, we will not attempt either to fully articulate the new paradigm or to fully describe the new biological techniques that we believe will contribute to it. Instead, we will incorporate gender consciousness into critiques of the rational actor 
model by revisiting Carol Gilligan's critique of Lawrence Kohlberg's account of moral development. This effort will provide a lens on the relationship between the demise of the rational actor, the rise of the new paradigm, and feminism. In the process, we will argue that Gilligan's articulation of relational feminism, while it rests on many of the attributes that behavioral biology and economics also emphasize, faltered, in part, because Gilligan could not identify the source of the stereotypically feminine values she wished to revalue. Second, we will consider the ways in which the limitations of the rational actor model mean that law and economics could also not resolve the relational concerns that Gilligan raised. Third, we will discuss the shift across disciplines that has made the social meaning of Gilligan's critique more salient. This shift should prompt reconsideration of Gilligan's project of revaluing "feminine" concern about relational values as a necessary counterpoint to the "masculine" inclination to create hierarchies and to overemphasize material advantage. This idea of balance, opposed to maximization or conflict, may be an essential element of the new paradigm.

\section{Relational Feminism Revisited}

Kate Bartlett defined feminism in 1990 as "asking the woman question" or identifying "the gender implications of rules and practices which might otherwise appear to be neutral or objective."

Initially, this produced a focus on equality: inclusion of women on the same terms as men. It soon moved to consideration of the ways in which women's perspectives differed from men's. Women in rape cases, for example, asked "why the defense of consent focuses on the perspective of the defendant and what he "reasonably" thought the woman wanted, rather than the perspective of the woman and the intentions she 
"reasonably" thought she conveyed to the defendant" (Bartlett 1990). As a result of the changed perspectives, rape laws changed and, indeed, Michigan eliminated the consent issue altogether and other states revised what had been immunity to charges of rape within marriage (Chamallas, 1988). These reforms occurred partly because the articulation of women's perspectives altered perceptions of justice for men as well as women, and partly because the inclusion of women in political and legal circles changed the balance of power.

Feminist concerns quickly shifted, however, from easily remedied examples of formal inequality to circumstances in which men and women's situations were not the same. Consider, for example, the issue of pregnancy discrimination. The Supreme Court held that, since only women become pregnant and not all women do, differences in the treatment of pregnancy from other medical conditions were not "sex discrimination." Congress responded by amending Title VII to bar discrimination in employment on the basis of pregnant status (Becker et. al., 2001). Feminists of the time argued that gender equality and full social inclusion required not just equal treatment, but consideration of the ways in which women differed from men, and inclusion of "feminine" as well as "masculine" values in the definition of the good society.

Carol Gilligan galvanized this discussion with her 1982 book, "In a Different Voice." In that work, she criticized the research of Harvard developmental psychologist Lawrence Kohlberg. Building on Piaget's development theories, he had constructed six stages illustrating the development of moral judgment on the basis of an empirical study of eighty-four boys whose development he followed over the course of twenty years 
(Gilligan 1982). ${ }^{8}$ Gilligan used the application of Kohlberg's theories to two prototypical eleven-year-olds, Jake and Amy, to capture Kohlberg's psychologists' failure to value the "relational caring voice" stereotypically associated with women.

Kohlberg had presented his test subjects with the following dilemma:

In Europe, a woman was near death from a very bad disease, a special kind of cancer. Doctors thought that there was one drug that might save her. It was a form of radium that a druggist in the same town had recently discovered. The drug was expensive to make, but the druggist was charging ten times what the drug cost him to make. He paid $\$ 200$ for the radium and charged $\$ 2,000$ for a small dose of the drug. The sick woman's husband, Heinz, went to everyone he knew to borrow the money, but he could get together only about $\$ 1,000$, which was half of what it cost. He told the druggist that his wife was dying and asked him to sell it cheaper or let him pay later. But the druggist said, "No, I discovered the drug and I'm going to make money from it." Heinz got desperate and broke into the man's store to steal the drug for his wife.

1982).

Should the husband have done that? Was it right or wrong? (Gilligan,

Jake constructs the dilemma, as Kohlberg did, as a conflict between the value of

Heinz's wife's life, and the value of the property to the druggist (Gilligan 1982). He sees the issue "sort of like a math problem with humans," with only one possible solution. At eleven, he is confident of his answer. He believes in the power of logic. He uses a hierarchical approach to select one value over another. And since his answer is rationally derived, he assumes that anyone else would reach the same conclusion, and that a judge

\footnotetext{
${ }^{8}$ The Six Stages, found at http://www.nd.edu/ rbarger/Kohlberg.html, are:

$\begin{array}{lll}\text { LEVEL } & \text { STAGE } & \text { SOCIAL ORIENTATION } \\ \text { Pre-conventional } & 1 & \text { Obedience and Punishment } \\ & 2 & \text { Individualism, Instrumentalism, } \\ \text { and Exchange } \\ \text { Conventional } & 3 & \text { "Good boy/girl" } \\ & 4 & \text { Law and Order } \\ \text { Post-conventional } & 5 & \text { Social Contract } \\ & 6 & \text { Principled Conscience }\end{array}$
}


"would also consider stealing to be the right thing for Heinz to do," and that the judge would thus give him a light sentence (Gilligan, 1982).

Amy, also eleven and planning to become a scientist, took a different approach to the dilemma. She saw it as "a narrative of relationships that extends over time" (Gilligan, 1982). In contrast with Jake's confidence, she seems evasive and unsure. She considers the effect on the wife if Heinz were to be imprisoned and unable to care for her. She would encourage Heinz to go back and try to change the druggist's mind. She holds to the idea that it is wrong both to permit the wife to die, and for Heinz to have to steal. While enjoys solving the question posed, which asked him to justify Heinz's behavior, Amy is puzzled by the druggists' indifference. Her firmest conclusion is that if Heinz were to persist, he would eventually find a way to persuade the druggist to provide the drug (Gilligan, 1982). If this were a law school exam, Jake would earn a higher grade than Amy, and for similar reasons, including his greater willingness to answer the question posed, he ranks more highly on Kohlberg's test of moral development (Hartwell, 1995) ${ }^{9}$

Gilligan objected to the higher rank given the "ethic of justice" that valorized hierarchical thinking over the "ethic of care" that paid more attention to relationships. Her critique, with its contrast of "webs" and "ladders," inspired a firestorm of reaction. It generated a new wave of feminism that sought to identify and revalue the traditionally feminine and traits associated with women across a wide variety of fields. The discussion also helped invigorate an emerging debate between communitarians and libertarians. Feminists joined communitarians such as Michael Sandel in identifying liberalism with an impoverished conception of individual actors that celebrated

\footnotetext{
${ }^{9}$ For a discussion of potential applications to the law school world
} 
independence at the expense of connection. The new movement identified women's perspectives with greater emphasis on human relationships, and greater concern for the emotional quality of human interactions (West, 1988).

Following Gilligan, a generation of relational feminists celebrated connection and care and context, examining the interaction between the individual and her location within a larger society. Relational feminism sought to explore the internal construction and parameters of particular relationships, as well as the place those relationships occupy in the external world. It emphasized the development of values that would serve as an alternative to hierarchy and competition. The concept of connection became an important touchstone for both "cultural" and radical feminists. Robin West explains: "Underlying both radical and cultural feminism is a conception of women's existential state that is grounded in women's potential for physical, material connection to human life, just as underlying both liberal and critical legalism is a conception of men's existential state that is grounded in the inevitability of men's physical separation from the species." (West, 1988, p. 14). This "physical, material" connection symbolizes the ability of women to focus on relationships.

Connection is, of course, not a monolithic concept, and inherently encompases principles of empathy and intimacy. Through empathy, we can "understand[] the experience or situation of another, both affectively and cognitively." (Henderson, 1987, p. 1579). Empathy allows us to draw on our own experiences so that we can understand, and thus feel connected to, others.

While Gilligan's contributions to developmental psychology are undeniable and while the influence of relational feminism remains strong in fields such as education, 
relational feminism soon foundered on two issues that divided feminists. Is the relational critique Gilligan championed in fact about gender differences, and if it is, what is the source of the differences? Many feminists attacked the idea of gender essentialism, that is, the claim that women share "essential" qualities that distinguish them from men, or common experiences that give all women similar perspectives (Abrams 2001). ${ }^{10}$ Indeed, researchers have questioned whether what Gilligan observed is about gender at all. Subsequent studies, for example, administered Kohlberg's questions to larger groups without necessarily finding that boys and girls answered the questions differently (See Tavris 1992, Friedman et. al. 1987, Thomas 1986, Walker 1984, Rothbart et. al. 1986, Ford and Lowery, 1986). ${ }^{11}$

Gilligan, however, never claimed that she was describing women's distinctive; she only wanted to revalue that associated with the stereotypically feminine. This nonetheless left open the source of the stereotypes. A famous exchange between Gilligan and Catharine Mackinnon illustrates the dispute:

Gilligan: Your definition of power is his definition.

Mackinnon: This is because the society is that way, it operates on his definition, and I am trying to change it. Gilligan: To have her definition come in?

Mackinnon: That would be a part of it, but more to have a definition that she would articulate that she cannot now, because his foot is on her throat.

Gilligan: She's saying it.

Mackinnon: I know, but she is articulating the feminine. And you are calling it hers. That's what I find infuriating.

\footnotetext{
${ }^{10}$ Noting that opposition to gender essentialism became an important component of feminism following Gilligan.

${ }^{11}$ Friedman et. al. 1987 finds no differences between men and women. Thomas 1986 finds that when such factors as education and socialization are accounted for, women score higher than men. Walker 1984 finds when education and socialization factors are removed, women score no different than men. Rothbart et. al. 1986 tests college students and finds that, although both men and women used different types of reasoning, women were somewhat more likely to respond in terms of care and men in terms of rights. Ford and Lower 1986 finds that more feminine males were more likely to use the ethic of care than less feminine males.
} 
Gilligan: No, I am saying she is articulating a set of values which are very positive.

Mackinnon: Right, and I am saying they are feminine. And calling them hers is infuriating to me because we have never had the power to develop what ours really would be (Gilligan 1985, see Gilligan 1986, Gilligan 1988). ${ }^{12}$

Mackinnon concluded that even if Amy's responses can in fact be linked to a distinctive women's perspective, there is no reason to believe that the views "are theirs," that is, that they represent the authentic views of women. She argued that women may have learned to value care because caring for men was what men valued, and that to emphasize women's orientation toward care without emphasizing the context of the constraining social construction in which it emerged was an "insult to [women's] possibilities" (Abrams 2001). Following the attacks on Gilligan, feminism fractured. It placed greater emphasis on Mackinnon's power analysis than on Gilligan's ethic of care, and on identifying women's diverse perspectives than on defining a common agenda (Abrams 2001). While Gilligan's method - giving voice to the girls' in her interviews and linking their views to the developmental steps in moral reasoning - made sense in the context of her field, it did not provide a satisfying way to address relational issues across the academy.

\footnotetext{
${ }^{12}$ Gilligan 1985 has responded to the controversy over men's and women's test scores by arguing that critics have mistakenly viewed In a Different Voice as a statistical argument for sex differences in moral development, an argument which these critics then rebut by showing no sex differences exist. She asserts that her argument is interpretive and not empirical, and that women constitute themselves in a morally different way even when they score no differently then men. Gilligan 1986 maintains that women are more inclined than men are to use a "care" orientation. Summarizing the findings of six different studies, Gilligan has noted that among the $92 \%$ of the women who stated that they used a "care" orientation, $62 \%$ preferred it; among the $62 \%$ of the men who stated they used a "care" orientation, only $7 \%$ preferred it. Among the $77 \%$ of the women who stated they used a "justice" orientation, $38 \%$ preferred it; $100 \%$ of the men stated they used a "justice" orientation and $93 \%$ preferred it. Men's preferences are decidedly more one-sided than women's: not only do all men overwhelmingly prefer the "justice" orientation (93\%), a large minority of men $(38 \%)$ exclude the "care" orientation completely.
} 
At the end of day, although relational feminists retained their conviction that women's ability to connect should receive equal weight with men's preference for separation and hierarchy, they could not ultimately answer the question whether these differences are nature or nurture -- whether the ethic of care arose from women's innate character or simply reflected values developed because men had "their feet on women's throats" (Abrams 2001). ${ }^{13}$ And, to the extent that relational feminism reinforced the association between women and care - rather than the promotion of alternative values then feminists feared it would be used to undercut women's other claims for equality.

\section{The Rational Actor Model in Feminist Context}

If Gilligan could not ultimately identify the source of the relational values associated with the stereotypically feminine, neoclassical economics marginalized or bracketed relational concerns (Carbone 1990). ${ }^{14}$ Neoclassical economics has long rested on the rational actor model; that is, predictions of human behavior that assume that people act rationally "to maximize their utility according to their preferences," that their preferences are exogenous, information and transactions are costless, and markets work perfectly (Dau-Schmidt 1997). These assumptions, which expressly exclude consideration of the feedback loops that occur when preferences depend on the reaction of others, give neoclassical economics its predictive power. The assumptions also make

\footnotetext{
${ }^{13}$ Professor Kathryn Abrams describes the demise of the "first generation care," maintaining that its downfall was its essentialism in suggesting that care was a central activity in most women's lives, and its failure to produce specific policy prescriptions or legal approaches.

${ }^{14}$ Indeed, in the cases in which non-material interests are paramount, law and economics often labels and marginalizes such concerns by referring to them as "psychic benefits." For example, one author argued that the only interest a wife might have in pursuing paid employment, rather than the supposedly efficiency maximizing role of specializing in domestic chores, was her "psychic satisfaction" in having her husband perform more housework. Carbone has argued elsewhere that "[m]issing altogether from ... [this] analysis is the fact that many women prefer their jobs to remaining at home, that society accords greater prestige to paid employment, and that economic independence has a dramatic effect on the power relationships within marriage and on women's status within society generally."
} 
law and economics a double-edged sword for feminists; the rational actor methodology is as least as impoverished as Kohlberg's model in dealing with Amy's relational concerns, but it does it does not hesitate to explain Amy's lack of power or earning capacity in terms of her "revealed preference" for an ethic of care.

Let us return to the example of Heinz and the druggist. Kohlberg used the example to chart the progression of moral reasoning. A neo-classical economist would use the example to predict behavior. If Heinz is assumed to act "rationally," the economist would predict that he is likely to steal the drug if he values the possibility of saving his wife's life more than the negative consequences of stealing the drug. The economist's evaluation of Heinz's preferences would take them as exogenously determined and stable over time; Crespi explains that for economists to treat preferences as exogenous means that the preferences "are viewed as innate personal characteristics that have a pre-legal, pre-political, acontextual existence, and are not affected by the legal rules that determine people's initial entitlements and govern their conduct" (Crespi 1997, Does the Chicago...). Accordingly, economic models, much like Kohlberg's models of moral reasoning, would approach Heinz's act as independent of Amy's concerns about the wife's reaction to Heinz's possible imprisonment (a contextual factor), or of the law's condemnation, condonation or mitigation of the act of theft in these circumstances. Indeed, an economist would treat Heinz's act of stealing the drug (since he has already done so in Kohlberg's story) as a revealed preference - a rational Heinz must value the drug more the consequences of the theft if he is willing to steal it.

The neoclassical model uses the same techniques even when the question shifts from the positive (predicting Heinz's behavior) to the normative (determining whether 
the law should encourage or deter Heinz's theft). To the extent that neo-classical economists propose normative approaches, they tend to advance theories that maximize utility (Dau-Schmidt 1997). ${ }^{15}$ Take the example of a hiker, starving and lost in the woods, who breaks into a privately owned cabin and steals food in order to survive. When charged with breaking and entering, trespass or theft, he claims the defense of necessity. ${ }^{16}$ Richard Posner (1998) observes that the necessity defense "will usually succeed if there is a very great disparity between the cost of the crime to the victim and the gain to the injurer." Richard Parry notes that "[a]t least one federal court has expressly declared that necessity is 'a utilitarian defense' based on "maximizing social welfare... where the social benefits of the crime outweigh the social costs of failing to commit the crime" (Parry 1999 citing United States v. Schoon, 971 F.2d $193\left(9^{\text {th }}\right.$ Cir. 1991)). Parry concludes that "this approach, which insists that necessity turns solely on 'avoiding the greatest amount of harm at the least cost,'... says nothing about the moral desirability of the defendant's choices or conduct. . ." (Parry 1999). David Friedman (2000), however, disagrees, maintaining that the "just" approach and the "efficient" approach often coincide, and that rules promoting efficiency are likely to also produce desirable conduct. ${ }^{17}$ After all, our society is hardly likely to conclude that the hiker should starve to death to avoid breaking into the cabin.

Nonetheless, even without taking Parry's concerns into account, a utilitarian calculus does not easily resolve the issue of Heinz and the druggist. Heinz, like the hiker in the woods, is likely to value his wife's life more than avoiding the act of theft, and as the responses to Kohlberg's study suggests, most people are likely to agree with him.

\footnotetext{
${ }^{15}$ For a summary of the different theories.

${ }^{16}$ See Model Penal Code $3.02 \mathrm{cmt} .1$ (1985).

${ }^{17}$ Friedman, however, does not claim that all utility maximizing acts should necessarily be legal.
} 
Unlike the hiker, however, Heinz has had an opportunity to propose an exchange to the druggist, and the druggist has turned him down. We are not told why. The druggist may have a limited supply of the drug and may prefer the higher (or at least more immediate) amounts other customers can pay. The druggist may have a patent that creates a temporary monopoly and may be convinced that altering the price for one customer will create pressure to reduce the price for many customers who, unlike Heinz, can afford to pay the higher amount. The druggist may dislike or distrust Heinz or may be acting irrationally. The story sets up a market in which the druggist is the only possible supplier; without perfect competition, there is no reason to assume that a Pareto optimal bargain will occur even if one clearly exists.

A court faced with Heinz's prosecution for theft would therefore face a dilemma. If it excused Heinz's act, it might encourage others to steal in the face of less exigent circumstances. Indeed, publicly excusing the theft might undermine the strength of the internalized norms against theft, even if there were agreement that this theft is justified. Posner, in adopting a utilitarian approach to the necessity defense, emphasized that the defense was likely to be applied where there was a "very great disparity between the cost of the crime to the victim and the gain to the injurer," not just where the gain to the thief outweighed the cost to the victim. The necessity defense works only if limited to relatively extreme cases. ${ }^{18}$ Uncertainty that it will applied helps insure that only those facing no real alternatives will act without first exhausting other possibilities.

\footnotetext{
${ }^{18}$ Indeed, Friedman explains that if the legality of theft were to be determined solely in accordance with a utilitarian calculus (that is, a determination that theft was permissible whenever the gain to the thief outweighed the loss to the owner), it would encourage rent-seeking, and therefore wasteful expenditures by both potential thieves and those seeking to secure their possessions. After all, many thefts may be utility enhancing without involving legal necessity (e.g., a thief who values a gold chain more than the wealthy owner, but lacks the resources to be able to purchase it.)
} 
On the other hand, failing to excuse the theft in these circumstances might bring the entire property regime underlying drug sales into disrepute. This example, if it were to turn on the druggist's patent or a monopoly position based on trade secrets, replicates some of the dilemmas underlying pharmaceutical manufacture. The specter of people dying because of their inability to afford a drug that costs little to produce strikes many people as unfair. An extensive literature from Talcott Parsons through Jurgen Habermas (1990) explores the role of legitimacy in holding together parts of society with divergent interests. A group systematically excluded from access to life-saving drugs in the face of an epidemic might view Heinz's conviction for theft as cause for rebellion. The choice of whether to excuse or mitigate Heinz's act of theft might therefore turn, as a matter of policy, on which risk is greater: undermining internalization of the norms against theft by excusing Heinz's flouting of the rules, or calling the legitimacy of the norms into question by applying them in a case in which the druggists' refusal to sell to Heinz's might be perceived as unjust.

In the face of this type of analysis, Kenneth Dau-Schmidt (1997) has called for relaxation of the assumption of exogenous preferences to permit consideration of the role of law in shaping norms, which of course in turn affects individual utility. He argues that a major objective of the criminal law, as these examples suggest, is to shape preferences, and any assumption of exogenous preferences is descriptively inaccurate, and implicitly promotes the status quo (Dau-Schmidt 1997). Gregory Crespi (1997, Reply) responds:

Unfortunately, if the exogenous preferences assumption is relaxed, the Chicago School models will no longer be able to provide determinate predictions, since we are as yet unable to formulate precisely when and to what extent our policies will impact preferences.... 
We face a difficult choice. We can continue to use restrictive Chicago School models which obscure several crucial questions raised by the fact that many policies do alter preferences: Which preferences should be favored? Which preferences should be disfavored? And what is the appropriate role of the state in shaping individual preferences? Or we can relax the assumptions of our models to allow for endogenous preferences but then find that we are unable either to predict or evaluate the results of our policies. Do we prefer tunnel vision or total blindness?

At the end of the day, the dilemma posed by the question of exogenous or endogenous preferences is not so different from that Gilligan faced. It is obviously correct to observe that the law influences people's values and that Heinz's decision to steal or not steal the drug depends in part on the value he places on observing the laws against theft. In addition, whether or not the druggist's motivation for turning down Heinz's proposals affects Heinz's willingness to steal the drug, it certainly affects the perceived legitimacy of a regime that would punish Heinz. Amy's relational concerns are an important component of public policy just as they are an important component of moral development. Crespi's challenge to Dau-Schmidt echoed Mackinnon's challenge to Gilligan; once we acknowledge the salience of these concerns, what framework do we have for evaluating them? How do we know whether they are or should be "hers"? Equally importantly, how do we know whether they should be "ours;" i.e., a basis for determining law and policy?

While law and economics thus offers limited tools for addressing the social meaning of legal rules, it has no difficulty dealing with the differences between Jake and Amy's moral preferences. Let the market decide! Indeed, it is arguable that, in the nineties, the intersection of law and economics and feminism guaranteed the dominance of radical feminism over relational feminism, and the clash between feminism and 
evolutionary biology delayed the more extensive introduction of biological methods into law and the social sciences. These disputes occurred, in part, because economics, with its bracketing of the initial distribution of resources and emphasis on revealed preferences, assumed that existing gender roles reflected an optimal allocation of responsibilities. If a druggist motivated by the ethic of care (read female) were to be more likely to value the benefit to Heinz's family over the additional profit she might earn from an alternative transaction, it would simply be an example of the brilliance of the market in action - no matter what the cumulative effect of the positions of female versus male druggists. The justice of the overall result would not be on the table, the collective action issues (e.g, care-oriented druggists might prefer a norm requiring a shared obligation to assist Heinz) would be marginalized, and the norm creation process (do druggists develop an obligation to make life-savings drugs available at something less than the full market price?) would be opaque.

In this context, consideration of gender differences, whether innate or culturally constructed could be hazardous. Gary Becker (1981), for example, in his Nobel Prize winning extension of the realm of economics to the family observed that:

Although the sharp sexual division of labor in all societies between the market and household sectors is partly due to the gains from specialized investments, it is also partly due to intrinsic differences between the sexes.

... [B]iological differences in comparative advantage explain not only why households typically have both sexes, but also why women have usually spent their time bearing and rearing children and engaging in other household activities, whereas men have spent their time in market activities. This sexual division of labor has been found in virtually all human societies, and in most other biological species that fertilize eggs within the body of the female.

The observation triggered in one short paragraph feminist fear and loathing for economics and biology. Here is the seemingly neutral use of economics to justify the 
world as it is (or more accurately by the time Becker wrote, was) on the basis of biology. Becker, ahead of his time on this one, even acknowledged the risk of stereotype threat, and deemed this, too, efficient. He reasoned that "deviant investments (medical education for women?) would presumably be more common if deviant biology (women unable to have children, women unwilling to be homemakers, or women more likely than their husbands to succeed in the medical profession?) were more common -- or if it were revealed at younger ages" (Becker 1981). Given the inability to predict these matters from childhood, Becker argued that it was easier for the utility maximizing parent to simply assume that girls should take home economics while boys study auto mechanics. Different comparative advantages (those trained to be auto mechanics could earn more than those trained to be homemakers) would then translate into advantages from specialization in home and market. It did not matter that Becker bracketed the power structure constraining women's choices and missed the much bigger aspect of specialization transforming women's lives, viz., the much more efficient specialization among women as women moving into the workforce brought home food from MacDonalds and hired other women to clean their homes and care for their children (see Carbone 2000). ${ }^{19}$ Economics celebrated the use of biology and equations to valorize the status quo, identifying women with a marginalized ethic of care in the process, even when this novel use of economics was palpably wrong (Fuchs 1988). ${ }^{20}$ In the meantime,

\footnotetext{
${ }^{19}$ Explaining that any decline in specialization between men and women when women entered the workforce in greater numbers was minor in comparison with the increase in specialization that occurred as women traded the generalist role of wife and mother for more specialized market functions, and used specialized market services to discharge their continuing domestic responsibilities.

${ }^{20}$ Indeed, Victor Fuchs, in a more sophisticated analysis of the family and labor market patterns underlying the transformation in women's roles, argued that it was the fact women cared more about children, not the fact that they cared for children, that guaranteed their economic subordination.
} 
they had very little to say about the wholesale change in norms that accompanied the reorganization of women's lives.

\section{Behavioral Biology Revisited}

"Only the most extreme proponents of sociobiology ... would assert that nurturance is or comes to be embodied in a particular portion of the brain." --Kathryn Abrams (1992)

"Oxytocin is increasingly recognized as important in facilitating bonding between mother and child and between sexual partners .... the role of oxytocin [is] supported by experiments with prairie voles, which have "faithful marriages," and montane voles, which do not. When each species received the same amount of oxytocin, they reacted differently, with prairie voles exhibiting "all the characteristic symptoms of monogamy, such as a strong preference for one partner and aggression toward other voles," while the same injections did not affect the behavior of the montane voles."

Carbone and Cahn (200?)

What is the promise of neuroeconomics? This nascent field has converted a fast-growing set of laboratory results into an impression of great promise to change our understanding of choice and rationality. Using magnetic resonance imaging (MRI) technology, neuroscientists observe blood flow in the brains of people engaged in familiar tasks of reasoning and choice. The preliminary results already suggest much about which regions of the brain engage in which dimensions of reasoning, choice, and moral judgment. Like alchemists who dreamed of finding an elixir of life and mystics who labored to see the face of God, investigators now speak of "seeing utility." What we have seen only in a mirror darkly, we might now meet vividly and immediately. And in an age when both economics and biology have vast reach and authority in the academy and the larger culture, the analogy to encountering life's essence or God's person might not be altogether far-fetched. For the first time, we could unveil and examine the hidden logic of our lives. This is the promise.

$$
\text { --Jedidiah Purdy (200?) }
$$

Fifteen years later, we do have better understandings of the impact of both biology and social construction on the development of sex roles, and of the role that science might play in helping us understand social construction. These insight will come, not from discovering a region of the brain controlling nurturance, but as Owen Jones and Tim Goldsmith emphasize, from "the integrated, interdisciplinary efforts of cognitive 
scientists, neuroscientists, and evolutionary biologists as well as social scientists in psychology, anthropology, economics, and related disciplines" (Jones and Goldsmith 2005). The use of a broad interdisciplinary approach to address questions long posed by law, economics, and moral reasoning offers to remake what Crespi termed as the choice between "tunnel vision or total blindness." These techniques also promise to revitalize relational feminism and to make possible a renewed focus away from individual actors and back toward a more self-conscious understanding of social meaning. To do so, however, will require of confronting - and transcending - the issue of gender.

\section{A. Feminist Fear and Loathing}

During the same period that Carol Gilligan touched off a wave of excitement about the potential revaluing of the stereotypically feminine, E. O. Wilson set off a wave of revulsion in the same circles with his work on sociobiology. Wilson, whose scientific career focused on the study of ants, argued that the same evolutionary analysis that explained insect evolution could be applied to humans. These evolutionary methods incorporate Charles Darwin's basic insight that "only those traits helping individuals to improve their reproductive success can proliferate" (Jones 1997).

To understand why Wilson's book on sociobiology was controversial consider a simplistic application to Heinz and the druggist. To the extent Gilligan claimed that "Amy" was more sensitive to the relational concerns in the story, evolutionary analysis might speculate on the reason why. That speculation is likely to focus on two differences between men and women. First, because women become pregnant and give birth and men do not, women can have fewer offspring than men (Baker 2000). Second, (and partly as a result of the first), 
women are more likely to care for children, particularly very young children than men (Baker 2000). Given that women provide the majority of care for children, the children of women more sensitive to their needs are more likely to survive, and thus women are more likely than men to be sensitive to relational concerns.

Feminists were and continue to be extraordinarily wary of such analysis because, as the discussion of Becker's Nobel Prize winning work suggests, such insights play out in the context of a debate between libertarians who celebrate the results of unregulated market processes as the reflection of women's "revealed" and presumptively authentic preferences and social constructivists who see market transactions as the product of the existing allocation of power, and therefore unlikely to maximize either individual (read women's) happiness or collective well-being. Libertarians, in contrast, including many of those who embrace the rational actor model, distrust social constructivists because they fear that the emphasis on power authorizes authoritarian countermeasures (see e.g. Ridley 2003). ${ }^{21}$

In a classic debate in the early nineties, Richard Epstein and Kathryn Abrams explored the implications of biology in exactly these terms. Like Becker, Epstein argued that if there is even a slight predisposition for women to nurture, then it becomes economically rational for women to specialize in nurturing roles. In relying on this analysis, Epstein (1992) alleged that a maternity leave program indicates that social construction is equivalent to "massive coercion by the state in support of dubious schemes of social control that could never earn their place in an open market." Instead,

\footnotetext{
${ }^{21}$ Commenting on B.F. Skinner's work, and the conclusion that Skinner's fiction, which envisions a world entirely produced by conscious human design, is a fascist state.
} 
In occupational categories that are heavily dependent on spatial differences, say, for example, architecture, we should expect to see men, on balance, do somewhat better than women in a perfect market because their natural endowments now turn out to be more suitable for the task. But if there are other occupations, such as counseling and guidance, that demand more of the nurturing and intuitive skills associated with the female roles in child rearing, then women should be at a relative advantage to men in seeking these positions . . radical changes in social organization will not obliterate the importance of critical biological differences (Epstein 1992).

In response, Kathryn Abrams observed that it is critical that "gender-specific differences are understood to be complex, changeable phenomena rather than biologically ordained mandates," and that, consequently, Epstein's arguments become even "less clear" (Abrams 1992). In a hunter-gatherer society, the average man might have an advantage over the average woman in spatial reasoning without necessary implying either that no woman should pursue a career as an architect, or that the average female applicant would necessary be less successful than the average male applicant in architectural school. For Abrams, the results are a result of conscious social choices critical because of their impact on women's relative standing in society. For Epstein, they are about freely made, "efficient choices;" any more direct intervention to alter the outcomes will be a heavy-handed exercise in futility.

Unsurprisingly, therefore, feminists have met efforts to introduce biological observations into legal discourse with suspicion. Kingsley Browne (1995) charged that, "In contrast to the weighty burden of proof imposed on those urging a biological basis for sex differences in behavior, those arguing that sex differences are socially constructed have borne little burden at all." Richard Epstein (1992) similarly objected that feminists attempted to treat "social 
influences dominant to the exclusion of biological ones.. ${ }^{22}$ Indeed, as we look back to reiteration of generations of debate of nature versus nurture, it is clear that these conflicts reflect more than the level of scientific discourse in the era. David Strauss (1992), writing contemporaneously with Epstein and Abrams, argued that "people engage in the nature-nurture debate" because it "reflects attitudes. The view that 'it's genetic' goes hand in hand with an attitude that we cannot fight the status quo." Kathy Baker, one of the first legal scholars to explore the intersection between biology and feminism, observed that:

For years feminists have been describing a world in which sexual violence is pervasive, marriage is a Faustian and dangerous bargain for women, and caretaking is a huge amount of usually unrewarded work. This is the world that the biologists describe also. If the biologist's description is more frightening than the feminist one, it is only because of the common but unnecessary presumption that, because the world is that way, it must stay that way. No biologist believes this (Baker 2000).

For behavioral biology to escape the Epstein-Abrams gridlock of a decade ago, it has to transcend the debate between biological determination and the clean slate approach of the social constructivists -- and it already has. When Kathy Baker states "no biologist believes this," she is describing a revolution in genetics that promises to dissolve the centuries old dichotomy between nature and nurture. While evolutionary analysis provides a framework for understanding what we see, behavioral biology, as Jones and Goldsmith emphasize, has become increasingly integrated with modern advances in cognitive psychology, neuroscience and other fields that make it possible to test hypotheses, and in some cases to determine not

\footnotetext{
${ }^{22}$ Epstein also alleged, "Some radical feminists have taken the view that androgyny - the elimination of all sex-specific roles - is appropriate not only for the workplace but for the greater society at large ... I incline to the view that the biology of sex differences is profound, and influences not only the activities immediately related to courtship, reproduction, and child rearing, but also virtually every other aspect of human conduct" Epstein 1992, Forbidden Grounds.
} 
just correlations with observed behavior, but in some cases causal factors. ${ }^{23}$

These new understandings underscore the role of genetic predisposition, not in determining outcomes, but in priming the reactions to environmental conditions. Matt Ridley (2003) writes:

Genes themselves are implacable determinists churning out utterly predictable messages. But because of the way their promoters switch on and off in response to external instruction, genes are very far from being fixed in their actions. Instead, they are devices for extracting information from the environment. Every minute, every second, the pattern of genes being expressed in your brain changes, often in direct or indirect response to events outside the body. Genes are the mechanisms of experience.

The new biology takes seriously the idea that humans are a social species.

The challenge is to explain the genes that allow cultural transmission, that guide the more sophisticated coordination of human behavior (Ridley 2003). ${ }^{24}$ The new biology has little in common with the blank slate. It is likely to find that women are biologically predisposed to care for children and for that matter, that men better navigate spatial relationships in the open savanna. It nonetheless treats as the far more interesting question how humans coordinate the activities and resources necessary to move from caves to communally constructed log cabins to skyscrapers. And how, within that context, individual roles change. After all, the Dean of the School of Architecture at MIT describes the transformation of her

\footnotetext{
${ }^{23}$ The issue of causation is itself, however, incredibly complex. The association of activity in a given area of the brain with a particular behavior, for example, does not prove causation, nor does it determine the origin of the brain activity itself. But some controlled experiment may show, for example, that the injection of a neurotransmitter in fact alters certain behavior, or that blocking receptors for the hormone produces the opposite effect. Even these studies do not "prove" that a particular evolutionary explanation is correct, or the presence or absence of such receptors is necessarily determined by genetic inheritance.

${ }^{24}$ Culture seems to be the cart, not the horse- the consequence, not the cause, of some change in the human brain.
} 
profession from inclusion of a handful of women in the sixties to half of today's

classes at many elite schools. ${ }^{25}$

\section{B. Economics Revisited: The Need for Behavioral Biology}

If economics - and law - are to incorporate insights from biology, they are likely

to do so both because of the increased sophistication of behavioral biology and because our understandings of the questions economists pose have changed. Behavioral insights from a multitude of sources - empirical studies as well as biology - have shown the inability of the rational actor model to address the fundamental issues on the horizon. Whether or not true believers in the neo-classical model will change their fundamental approach or simply "tweak" their theories, the model itself is rapidly being supplemented - and supplanted - by alternative approaches (Nelson 2005, cf Kahneman 2003). ${ }^{26}$

Indeed, more sophisticated knowledge about behavior is already transforming core theories about democracy and the development of law. Cass Sunstein (2006), for example, has recently called for a "New Progressivism," which builds, in part, on the recognition that while command-control economies have been found wanting, so too has laissez-faire economics failed to promote democracy and prosperity in the developing world (Hayek 1944, Ramirez 2003). ${ }^{27}$ His New Progressivism would respect

\footnotetext{
25 "Santos's talk gives history of women in architecture," http://web.mit.edu/newsoffice/2005/santos0302.html

${ }^{26}$ As Nelson suggests, "Some economists ... have begun to explore the empirical implications of a richer psychological model of human behavior. This could lead to a very useful rethinking of core economic assumptions ... Or it may not. I believe that the ultimate usefulness of this research will depend on how willing my discipline is to let go of its one-sided worship of the ideals valorized in" the rational choice model.

${ }^{27}$ Indeed, the political dominance of the neo-classical model arguably begins with Van Hayek's The Road to Serfdom, which argued that state intervention in the market, because of its intrinsic limitations, inevitably produced authoritarian regimes. Steven Ramirez observes: "There is no gentle way to put this: people all over the world are perishing upon the altar of the failed ideology of market fundamentalism. So says the 2001 Nobel laureate in Economics, Joseph E. Stiglitz, in Globalization and Its Discontents. This brand of market fundamentalism, emphasizing free markets, or market liberalization, and minimal
} 
fundamental rights, promote democracy, and strengthen economic development At the core of his essay is an effort to incorporate a more sophisticated understanding of human motivation into a redefined role for the state. His vision has three parts, beginning with

(1)a distinctive conception of government's appropriate means, an outgrowth of the late-twentieth-century critique of economic planning, and (2) a distinctive understanding of government's appropriate ends, an outgrowth of evident failures with market arrangements and largely a product of the mid-twentieth-century critique of laissez faire (Sunstein 2006).

The third element then focuses on the role of norms in ordering behavior. Sunstein (2006) emphasizes that social norms, especially when reinforced by government and celebrities, can have a more powerful shaping influence on behavior than government fiat or market incentives taken in isolation. He therefore reconsiders the types of legal interventions that can have such effects, suggesting the importance of developing "human capabilities in a way that is alert to the nature of incentives and the role of social norms" (Sunstein 2006). ${ }^{28}$ Sunstein's agenda depends in turn on different ways of thinking about law - and a more robust understanding of human motivation than the rational actor model can provide.

Dan Kahan, drawing on the insights from game theory, agrees that the role of law, at least in certain settings, should be to shape behavior through its effect on internal rather than external motivation, and that the self-conscious structure of legal institutions matters. Kahan focuses on a central limitation of the rational actor model: the inability to address "collection action" problems Prisoners" dilemmas games have increasingly focused on the extent to which human behavior, rather than simply reflect narrow selfinterest, in fact demonstrates a greater preference for cooperation than the rational actor

government intervention in the economy, is the direct spawn of the efficiency obsession that dominates law and economics."

${ }^{28}$ The significance of human capabilities to development is drawn from Amartya Sen's work. [cite]. 
model might predict. Consider, for example, research experience with the ultimatum game. In the game, one player proposes a division of a given sum of money, which the second player accepts or rejects. If the second player accepts the proposed division, then both players claim their respective shares of the money. If the second player rejects the division, however, the pot of money "dissolves" and neither player takes anything (Purdy forthcoming). The rational actor approach suggests that the first player should propose the minimum amount necessary to get the second player to accept, and the second player should accept what is offered because otherwise neither player receives anything. In fact, student subjects most commonly offer $50 \%$, and about half the time respondents reject offers below twenty percent (Henrich et. al. 2005). Moreover, while students' experiences were consistent cross-culturally, studies with hunter-gatherers or nomadic tribes varied. Researchers found that the greater the degree to which subjects participated in market transactions, the more likely they were to offer higher amounts (Henrich et. al. 2005).

Biology adds further insight. When researchers linked fMRI results to experiences with the ultimatum game, they also found distinct brain patterns associated with reciprocity and fairness. In responding to offers perceived as unfair, subjects showed activity in two parts of the brain: the dorsolateral prefrontal cortex (DLPFC), associated with "cognitive processes such as goal maintenance and executive control," and the bilateral anterior insula (BAI), associated with "negative emotional states" such as anger and disgust as well as with sensations of hunger and thirst (Sanfey et. al. 2003, see also Cohen 2005). Purdy reports that: "Not only were both regions engaged by unfair offers attributed to human offerors; but activity in the BAI was higher while considering 
offers that respondents rejected than while considering offers they accepted" (Sanfey et. al. 2003, Purdy forthcoming). These findings suggest that the decision to accept an "unfair" offer depends on the balance between the level of anger the offer provokes, and the strength of the cognitive determination to accept it as a matter of self-interest. Purdy concludes that, while perceptions of reciprocity and fairness may be widespread, both the strength of the emotional reaction to low offers, and the cognitive willingness to override such reactions may be learned behaviors (Purdy, forthcoming). Not only are such "preferences" not exogenously determined, they are increasingly within reach of testing and study.

Kahan (2003), acknowledging the ultimatum game results (but writing before the fMRI images became available) emphasized the way such insights change the approach to collective action problems. He observes that these results show that, first, the assumption that people act to maximize narrow self interest is not necessarily true, and, second, there is no single equilibrium point toward which human behavior tends to move (Kahan 2003). Instead, the results depend on the extent to which the group promotes an atmosphere of trust. Kahan (2003) concludes::

Whereas the conventional logic of collective action counsels the creation of appropriate external incentives, the logic of reciprocity suggests the importance of promoting trust. Individuals who have faith in the willingness of others to contribute their fair share will voluntarily respond in kind. And spontaneous cooperation of this sort breeds more of the same, as individuals observe others contributing to public goods and are moved to reciprocate. In this self-sustaining atmosphere of trust, reliance on costly incentive schemes becomes less necessary. By the same token, individuals who lack faith in their peers can be expected to resist contributing to public goods, thereby inducing still others to withhold their cooperation as a means of retaliating. In this self-sustaining atmosphere of distrust, even strong (and costly) regulatory incentives are likely to be ineffective in promoting desirable behavior. 
In other words, Kahan uses the insights of behavioral economics, without biology, to argue for the more self-conscious role of law in norm creation. Strategic intervention affects not just the incentives at the margin for the self-interested utility maximizing actor, but the interaction of the group: in a higher trust society, individuals internalize norms of reciprocity. Their preferences change to place greater value on the esteem in which others hold them, and to exhibit greater concern for avoiding the shame that would follow from the perception that they might be untrustworthy (Kahan 2003). ${ }^{29}$ These internalized norms, Kahan argues, are more effective in changing behavior, and in turn creating higher trust societies, than changes in external incentives. With these insights, legal scholars shift their focus from the marginal incentive effect of legal rules to the design of institutions.

Purdy, arguing that neuroscience will be critical to the next stage of economics, goes beyond Kahan to maintain that precisely what neuroeconomics offers is the ability to test the results of cultural norms or other interventions that may alter the balance between cognitive and emotional brain reactions. He explains that "the contribution of neuroeconomics is that economic self-interest and the reciprocity characteristic of trust have different correlates in the brain, and may well express distinct and potentially competing motivational systems. If this is true, then those who design legal systems should be alert to both the benefits of consonance between the systems and the hazards of

\footnotetext{
${ }^{29}$ Kahan observes that:

Finally, the conventional theory and the reciprocity theory differ on the variability of preferences across individuals. The conventional theory imagines that the disposition to free ride in collectiveaction settings is relatively uniform. In contrast, the evidence on which the reciprocity theory rests suggests that the disposition to cooperate varies. In public-goods experiments that generate multiple equilibria, for example, neither universal cooperation nor universal defection is the final resting point.
}

Id. at 78 . 
bringing them into conflict" (Kahan 2003). Chorvat and McCabe (2004) observe along the same lines that: "If [government] can frame violations of its rules as defections from social norms, they are more likely to be punished and often private punishment is enough to enforce this obligation. To the extent that society is able to frame defection as cheating and invoke social sanctions, enforcement will become easier."

Sunstein issued his challenge for the creation of a new "progressive agenda"; Chorvat and McCabe write within a tradition closer to the neo-classical school. Together with Kahan and Purdy, however, they all approach the application of behavioral biology to law in terms of legal interventions that consciously interact with social norms. Law, economics, and behavioral biology are all turning awat from models that assume narrow self-interest to broader consideration of cooperation, trust, reciprocity fairness - and the idea of morality (for more extensive examination of these issues see Zak 2007). ${ }^{30}$

\section{Moral Development in Behavioral Context}

If there is anything that serves to coordinate human behavior, it is the instillation and reinforcement of norms. Kohlberg's research focused on a systematic effort to understand the process of developing moral values, a critical component of norm institutionalization. Accordingly, the new biology may affect our understanding of Kohlberg at least as much if not more than our understanding of Gilligan. Kohlberg made two claims: that moral reasoning was a cognitive process, and that his stages of moral development were universal in the sense that individuals in different cultures necessarily moved through the different stages sequentially (that is, from stage one to

\footnotetext{
${ }^{30}$ The book rejects what the popular understanding of "free enterprise" as resting on self-interest and argues instead that market transactions depend on cooperation, which in turn reflects the internationalization of values such as honesty and trustworthiness.
} 
stage two to stage three without skipping from stage one to stage three). Both have been called into question.

Kohlberg attempted to test the cross-cultural applicability of his theory by repeating the studies in different cultures including Mexico, Taiwan, Turkey, Israel, the Yucatan, Kenya, the Bahamas, and India, and generally found the same stage sequence, with a greater percentage of some societies reaching the higher stages than others (Crain 1985). Later studies have suggested that only stages one through three are consistently cross-cultural (Ma 1984, see also Snarey 1985). ${ }^{31}$

More recent studies have attempted to isolate the factors that produce higher versus lower scores in different cultures on Kohlberg's measure of ethical reasoning. A study that compared Australian and Chinese auditors, for example, found that the Australians scored higher on Kohlberg's tests than did Chinese from either the mainland or Hong Kong. The authors suggest that "[h]igher ethical reasoning scores are consistent with societies whose values are classified by individualism, small power distance, short term orientation and strong uncertainty avoidance," and conclude that because Australian and Chinese culture differ on such measures, the Kohlberg's test is unlikely to produce the same results in comparable populations (Tsui and Windsor 2001, also see Al-Shebab 2002, but see Ma and Cheng 1996). ${ }^{32}$ These findings suggest that culture may well prime the cognitive frameworks for moral choice.

This type of study, however, is limited to the use of surveys that measure the articulation of reasons for moral decision-making. They cannot test ethical behavior, nor can they identify the source of cultural differences beyond the terms of ethical discourse

\footnotetext{
${ }^{31}$ Snarey 1985 finds support for the cross-cultural application of Kohlberg's scheme.

${ }^{32} \mathrm{Ma}$ and Cheng 1996 finds a closer cross-cultural results.
} 
in different communities (Compare, e.g. Nisbett and Cohen 1996). ${ }^{33}$ In contrast, Harvard's Cognitive Evolution Laboratory attempts to chart the actual process of moral decision-making by combining the type of moral dilemmas Kohlberg posed with fMRI's that identify the parts of the brain involved. Joshua Greene, an assistant professor of psychology involved in the studies, hypothesizes that emotional and "cognitive" factors compete for the control of behavior, and that different problems may trigger competing subsystems in the brain.

To test these theories, the Harvard lab uses the "trolley" dilemma. In this problem, the researchers ask:

A runaway trolley is headed for five people who will be killed if it proceeds on its present course. The only way to save them is to hit a switch that will turn the trolley onto an alternate set of tracks where it will kill one person instead of five. Should you turn the trolley in order to save five people at the expense of one? ${ }^{34}$

Most people say yes (see Thomson 1986). ${ }^{35}$ Now, consider Greene's second dilemma, the footbridge problem:

Once again, the trolley is headed for five people. You are on a footbridge over the tracks next to a large man. The only way to save the five people is to push this man off the bridge and into the path of the trolley. Is that morally permissible? (Thomson 1986).

Most people say no. Greene considers how to reconcile the different results. Using purely utilitarian reasoning, both examples involve sacrificing one person to save five. But in the second, the actor must physically push a person to his death. Greene et. al. (2001) hypotheses that the internalized restraints on such conduct involve different areas

\footnotetext{
${ }^{33}$ Attempts to link different cultural responses to physiological markers, such as rises in testosterone or cortisol levels after certain encounters.

${ }^{34}$ Available at http://www.wjh.harvard.edu/ jgreene/

${ }^{35}$ Green takes these dilemmas from Judith Jarvis Thomson, Johnson 1986.
} 
of the brain than the process of determining whether to throw a switch that will less directly produce someone's death. His fMRI analyses in fact show that subjects considering the first trolley car example were more likely to engage the areas of the brain involved in working memory (that is, the parietal lobes and the middle frontal gyrus) and higher cognitive function (Greene et. al. 2001). In contrast, the example involving pushing the fat man off the bridge activated areas of the brain associated with emotion (Greene et. al., 2001). Greene et. al. (2001) hypothesizes that the different results arise because the second example triggers a response from the parts of the brain regulating emotions that overrides the utilitarian calculus produced by the parts of the brain governing cognition and working memory. He concludes that these differing responses may also correspond to utilitarian versus deontological approaches in philosophy (see Greene in press, see also Greene 2002).

Greene suggests further that the involvement of different brain areas may explain some of the anomalies Kohlberg discovered in his own tests. In examining college students, Kohlberg found that students he had identified as stage five moral reasoners on one test performed at stage two on a subsequent test. Yet, Kohlberg identified stage two with young children displaying a naively egoistic world view, and his approach to developmental stages maintained that once an individual moved on to a higher stage, there should be no return to the earlier forms of expression (Greene 2002, see also Fishkin 1984). The results may be explained, however, by the existence of two different systems, with the stage five reasoning produced by the cognitive system and the stage two results produced by the emotional system. ${ }^{36}$

\footnotetext{
${ }^{36}$ Indeed, Greene reports that patients who have suffered.
} 
These results provide new tools in addressing normative issues. Greene emphasizes that his use of fMRI's produces a positive description of the operation of the brain, not endorsement of one normative conclusion over another (Green et. al. 2001, see Greene in press). ${ }^{37}$ But he clearly believes that the results have implications for implementing normative propositions. Take, for example, the punishment that the criminal law might impose on Heinz. The standard economic approach, using utilitarian reasoning, might recommend the punishment that would provide optimal deterrence in the future. Conversely, a retributivist approach would consider the extent to which Heinz's act deserved punishment. Greene cites a series of studies that show that, in meting out punishment, test subjects are much more influenced by emotional than cognitive factors. It is the level of outrage associated with the criminal act and not the punishment needed to deter that best explained choice of penalty in these studies (Green in press). fMRI studies confirm that the extent of punishment subjects inflict correlates the degree to which the punishment decision involves the parts of the brain associated with emotion (de Quervain et. al. 2004). These results suggest, at a practical level, that a randomly chosen jury is unlikely to inflict a serious penalty on Heinz in accordance with the facts of Kohlberg's scenario unless they feel outrage at Heinz's act, outrage that is unlikely in the absence of betrayal, injury to the druggist or another patient deprived of the drug, etc.

Marc Hauser, on the basis of Noam Chomsky's linguistic theories, animal studies that demonstrate that other mammals display similar basic "moral" responses, and studies those like those using the trolley car dilemma, argues that humans have a universal moral

\footnotetext{
${ }^{37}$ Greene nonetheless argues for the bankruptcy of deontology as a form of moral philosophy because of the extent to which it rationalizes the results of emotional judgments. Greene believes that pushing the fat man off the bridge may be as justifiable as pulling the switch on the trolley car.
} 
grammar, an instinctive, unconscious tool kit for constructing moral systems (Hauser 2006). Other researchers, while not necessarily as deterministic, expect to find a high degree of consensus on such basic issues as the unacceptability of murder and incest, and an important role for culture in shaping the development of the mind to react to more culturally specific issues. [add cite] While the ability of legal analysis to incorporate the insights from the new science is in its infancy, greater understanding of the neurological basis for moral judgments changes the nature of Kohlberg's and Dau-Schmidt's undertakings - and sooner or later takes us back to Gilligan.

\section{Gilligan in Biological Context}

Research on the biological basis of gender differences has mushroomed in recent years, and the scholarly taboos against acknowledging gender differences may be waning At least three explanations immediately come to mind: first, the study of biology necessarily involves consideration of gender and the existence of at least some biological differences is obvious and undeniable; second, more sophisticated research techniques makes more nuanced findings possible and essential to the study of diseases as diverse as breast cancer and autism; and, third, a generation of women researchers have spearheaded the efforts.

The emerging literature on gender is vast and rapidly increasing. In considering the implication for law, economics and feminism, however, we wish to focus on two areas: game theory and the autism research that considers child development and a "theory of mind." Both rediscover (not always with attribution) the qualities Gilligan associated with the stereotypically feminine. We examine these findings, however, with a note of caution. The existence of differences in brain structure, development and 
function do not necessarily explain complex behavior, and even where some differences may be innate, they do not necessarily indicate either incapacity or immutability. Instead, gender may be more important in shaping preferences than abilities.

\section{A. Game Theory in Feminist Context}

Game theory, as we have discussed above, allows the empirical investigation and modeling of strategic decision-making. This empirical investigation allows researches to separate out the interaction of numerous attributes (including, most importantly for our purposes, gender) and preferences in studying behavior. Perhaps the best known "game" is the prisoners' dilemma in which two prisoners will receive short sentences if neither testifies against the other, but if one defects while the other remains silent, the first will go free while the second will receive a very lengthy sentence. Game theory began in the forties as a branch of mathematics, but it drew increasing interest in the seventies as the combination of cooperation and retaliation outperformed more "selfish" strategies in computer simulations (see Ridley 1996 for a summary of these developments). As the role of cooperation captured increased academic attention, so too did interest in testing gender differences in game theory performances.

Economists Croson and Gneezy (2005) have performed a meta-analysis of scores of studies involving the trust, dictator, ultimatum and other prisoner dilemma games conducted over decades of study. They find that:

We believe, as suggested by Gilligan (1982), that men's decisions are less context-specific than women's. Participants of both genders are likely maximizing an underlying utility function, but the function that men use is less sensitive to the conditions of the experiment, information about the other party, and (even) the other party's actions, than the function that women use. This causes what appear 
to be inconsistent results in our experimental studies; sometimes men appear more altruistic than women and other times, women appear more altruistic than men. But primarily what we see is women's behavior is more context-dependent than that of men.

Moreover, in subsequent research, they found that men tended to view trust more strategically than women, who instead focused on the relationships at issue (Croson et .al. forthcoming). Part of the way in which women are more context dependent is that their responses are more likely to vary if they can see the other person than if they are dealing with an anonymous subject behind a screen, or if they are given information such as a gender linked name (see also Croson and Buchan 1999). In the ultimatum game, for example, the initial offers vary relatively little between men and women or from one type of game to the next. The responders' behavior, on the other varies considerably. Where the parties could see each other, both men and women were more likely to accept offers from women, and women were significantly more likely than men to accept low offers (Croson and Buchan 1999). When the subjects sat behind a screen where they could not see each other, however, offers made by women were more likely to be rejected than offers by men (Croson and Buchan 1999). And women were also more likely to reject offers in the second study than in the first. The authors emphasize that not just does women's behavior change in the two studies, the swings in behavior are substantially larger than the male swings suggesting greater sensitivity to social context (Croson and Buchan 1999). ${ }^{38}$

The authors also examine studies designed to judge generosity. Here, they find that, when efficiency is not a factor, women give more than men. Where efficiency

\footnotetext{
${ }^{38}$ For example, when women are responders, they reject the offer $18 \%$ more often when they cannot see the proposer, while men reject offers only $8 \%$ more offer.
} 
considerations are added, men give more to the extent the donations enhance efficiency; women prefer more equal outcomes (Croson and Buchan 1999). More recent research confirms these differences. A spring 2006 study attempted to distinguish between those motivated by the desire to maximize social surplus (i.e., to increase the size of the pie) and those motivated by a desire to avoid inequity. The report finds "that those otherregarding individuals who can be classified are almost evenly split between inequity aversion and social surplus maximization. However, men and women have systematically different preferences, with women significantly more likely to be inequity averters and men more likely to be social surplus maximizers" (Kamas and Preston 2006). ${ }^{39}$ The authors conclude that some studies that attempt to measure altruism produce inconsistent results about gender effects if they do not distinguish between the different motivations.

Even more intriguingly, game theory experiments suggest that the interaction between men and women may change outcomes. In a carefully structured experiment, several economists found that when charitable giving was anonymous, women gave significantly more than men. When the charitable decisions were made in pairs, however, pairs consisting of one man and one woman give more than same-sex pairs, and all-male pairs give the least (Kamas et. al., 2006). The authors concluded that "men and women act more altruistically when in the presence of someone of the opposite sex suggesting that increased participation of women in economic affairs may lead people to behave more altruistically" (Kamas et. al., 2006).

\footnotetext{
${ }^{39}$ Showing that women were four times more likely than men to be inequity averters.
} 
These findings suggest that for the studies that attempt to tease out the elements of cooperation that make societies and markets function effectively, gender matters and women do in fact display an ethic of care. Economics by itself, however, can say very little about the source or persistence of the observed behavior. Nonetheless, as we have emphasized throughout this paper, biology helps us understand the behavior we observe, and it may help structure understandings about the parameters of social as well as natural construction.

. B. B. Biology and Gender Revisited

Speculation about the biological basis of gender has a long and checkered history. Much has been made of differences in brain size between men and women, but the latest studies seem to show that the effects if any are proportional; smaller people have smaller brains without effect on function (See Darlington 2002, see more generally Dekaban and Sadowsky 1978, see also Reiss et. al. 1996). ${ }^{40}$ More recent work on brain structure continues to show some gender differences in both shape and function, but it is not clear that these differences have much effect on complex behavior (Haier et. al. 2005). ${ }^{41}$

\footnotetext{
${ }^{40}$ In Dekaban and Sadowsky 1978, "Brain weight is greater in males than in females at all corresponding ages...The average difference for all ages in $9.8 \%$. In Reiss et. al. 1996, finding in a study of children that the absolute cerebral volume, which is the sum of the gray matter, white matter and cerebrospinal fluid, is approximately $10 \%$ larger in boys than in girls.

${ }^{41}$ In a recent study of 48 people, researchers examined general intelligence tests and MRI brain scans to determine any correlation between intelligence test scores and the amount of gray or white matter in the subjects' brains. The gray matter volume that correlated with the intelligence test constituted $9.6 \%$ of the full gray matter volume in males' brains, but only $1.7 \%$ of the gray matter volume in females' brains, while the white matter volume correlated to the test was . $1 \%$ of the total volume in male brains, and $1.3 \%$ of the total volume in females' brains. Each of the different types of brain material is associated with different strengths: white matter involves connecting various parts of the brain, while gray matter is involved in the processing of more localized information. Gray matter provides "concentrated processing power" and the capacity to connect thoughts, while white matter distributes processing capability but also promotes focus. The differences in brain composition and function did not correspond to differences in intelligence, though they may correspond to the way the brain coordinates the two hemispheres.
} 
Finally, studies that show that men and women in fact use different parts of the brain in solving problems do not necessarily conclude that men and women come up with different answers (Spelke 2005). ${ }^{42}$ Nonetheless, a growing body of research has focused on at least two areas that appear to find biological roots for the differences Gilligan observed.

The first involves the effect of hormones in priming fetal development. Male and female fetal development begin to diverge in the eighth week of pregnancy (Brizendine 2006). At that time, males typically experiences a testosterone surge that kills off cells in the communication centers of the brain, and contributes to the growth of more cells in the sex and aggression centers. Female fetuses, in contrast, experience much greater growth in the centers of the brain that process communication and emotion (Brizendine 2006, see Knickmeyer et. al., 2005). ${ }^{43}$

These fetal differences correspond to observed differences in toddlers. Higher rates of exposure in utero to testosterone, for example, are associated with diminished eye contact when a baby is one year and smaller vocabularies, but increased abilities at mental rotation during childhood (The Economist, 2006, Marano 2003, Lutchmaya et. al. 2002). Conversely, girls' ovaries produce a large amount of estrogen during their first two years of life, which may correspond to greater empathy and capacity for communication. Louann Brizendine (2006), for example, reports that:

\footnotetext{
${ }^{42}$ For example, on tests that involve navigating by geometric or landmark location, women use landmarks and men use maps. But when there is only one of those two sources of information available, then men and women perform equally.

${ }^{43}$ These stereotypical differences, of course, refer to the average male and average female. The testosterone levels and corresponding brain development differ among males and females. For a discussion of the possible role of testosterone in what Simon Baron-Cohen has referred to as "extreme form of the male brain" implicated in autism, see Knickmeyer et. al., 2005.
} 
A University of Texas study of twelve-month-old girls and boys showed the difference in desire and ability to observe. In this case, the child and mother were brought into a room, left alone together, and instructed not to touch an object. The mother stood off to the side. Every move, glance, and utterance was videotaped. Very few of the girls touched the forbidden object, even though their mothers never explicitly told them not to. The girls looked back at their mothers' faces ten to twenty times more than did the boys, checking for signs of approval or disapproval. The boys, by contrast, moved around the room and rarely glanced at their mothers' faces. They frequently touched the forbidden object, even though their mothers shouted, "No!" The one-year-old boys, driven by their testosteroneformed male brains, are compelled to investigate their environment, even those elements of it they are forbidden to touch. (pp. 16-17)

While not all of the developmental differences associated with gender translates into adult differences, researchers hypothesize that if gender is a factor in the sociocognitive factors that determine facility in the type of relational skills associated with Gilligan's gender analysis, then they would expect to see differences in three areas: facility in reading non-verbal cues, language and theory of mind (Geary 2002). With respect to the first, facility with non-verbal cues, studies generally do show significant gender differences. In an effort to tease out whether, as Mackinnon suggested, status effects may explain these differences, Judith Hall reports that for traits such as loud voice, interruptions, and speaking times, status parallels gender effects, with women demonstrating behavior associated with lower status (Hall 2006). However, with respect to traits thought to be associated with higher status, such as facial expressiveness, the ability to express emotions through non-verbal cues, and to accurately decode non-verbal cues in others, women outperformed men. Women also did so with respect to traits (smiling, gazing, touching, gesturing) thought to be unrelated to status (Hall 2006). These findings suggest that with respect to the traits most closely associated with non- 
verbal communication, women's greater abilities may be independent of higher or lower status. $^{44}$

The second category, language, is the most complex of the three. Most studies agree the women demonstrate greater verbal ability than men, but the studies show, for example, that while girls' language development proceeds more quickly than boys', resulting in greater vocabularies for girls at younger ages, gender differences in vocabularies do not persist into adulthood. On the other hand, women do outperform men in verbal memory, spelling and verbal fluency through adulthood (Knickmeyer et. al. 2005).

Finally, Simon Baron-Cohen and his associates at the Autism Research Center at Cambridge University have linked gender development to theory of mind, that is, the ability to make inferences about the intentions, beliefs, and emotions of other people in order to predict and explain their behavior (Knickmeyer et. al., 2005). These researchers hypothesize that "girls theory of mind may develop earlier in females and that girls and women are, on average, better at making inferences about people's mental states and adjusting their behavior accordingly" (Knickmeyer et. al., 2005).

While some studies suggest that these differences in ability may be attributed to, or accentuated by, differences in the social interests of girls and boys, a second category of newly developed research speculates that these capacities may be associated with the performance of mirror neurons. Indeed, the cover of Scientific American in November, 2006 featured a story on "Mirror Neurons and Autism," which explored the evidence associating mirror neurons with the abilities involved in theory of mind, reporting that

\footnotetext{
${ }^{44}$ Of course, this study cannot rule out the hypothesis that women enjoyed greater evolutionary advantages than men in developing these capacities because of their greater vulnerability.
} 
"dysfunctions of this neural system could explain some of the primary symptoms of autism, including isolation and absence of empathy" (Ramachandran and Oberman, 2006). The article noted that studies of people with autism show a lack of mirror neuron activity in several regions of the brain, at the same time that earlier studies have associated autism spectrum disorders with gender. These studies show, for example, that "[i]ndividuals with autism perform poorly on tests where females are usually superior to males, such as the 'Reading the Mind in the Eyes' test ..., but perform better than people without autism on tests where males usually outperform females, such as the 'Embedded Figures Task'” (Knickmeyer et. al., 2005). ${ }^{45}$

A new study, published in July, 2006, follows through on the implications of this research and attempts to test the relationship between mirror neurons and gender. Using the same EEG measurements that linked mirror neurons to autism, this research tested 10 girls and 10 boys to determine whether gender was a factor in mirror neuron functioning (Cheng et. al., 2006). The study showed that gender was in fact a factor, with the mirror neuron system in the women responding more strongly to pictures of a moving hand, while the men's mirror system reacted more strongly to pictures of a moving dot, while women's systems did not respond to the dot at all. The researchers concluded that the findings "appear in accordance with psychological and cognitive gender dimorphism, that is, women are stronger empathizers and men are stronger systemizers in the general

\footnotetext{
${ }^{45}$ The "mind in the eyes" test determines whether an individual can accurately decode the emotion expressed in photos of people's eyes. The embedded figures task involves picking a figure out of a background as in "Where's Waldo," a children's game that requires finding the character "Waldo" in a crowded scene.
} 
population" (Cheng et. al. 2006). ${ }^{46}$ Taken together, these results suggest that the hormones that produce gender may also be linked to interpersonal skills; ${ }^{47}$ girls on average may in fact bring greater sensitivity to the kind of relational issues Gilligan discussed (Cheng et. al., 2006, see Ramachandran, 2001). ${ }^{48}$

At this point we have come full circle. We are back to Gilligan and the traits she associated with the stereotypically feminine. Women are on average more relational, more sensitive to the reactions and emotions of those around them, more motivated by the desire to have an effect on others. ${ }^{49}$ While the discovery of mirror neurons is only ten years old, and their significance is not fully understood, we have laid out the growing case that these differences in behavior do correspond to differences in the organization and function of the brain. Ironically, however, these traits may be most closely associated with the neural evolution - viz., that of mirror neurons - that researchers are hailing as the key to human learning and flexibility (Cheng et. al., 2006, see

\footnotetext{
${ }^{46}$ We should emphasize, however, that the study included a number of caveats, including the suggestion that while they deliberately chose a gender-neutral looking male hand, that the study should be repeated with other more masculine or feminine hands. In addition, the research subjects were deliberately chosen to include only heterosexual men and women who reported no same-sex partners or sexual attraction.

${ }^{47}$ The researchers also looked at the role of fetal testosterone levels in social interactions among four-yearolds, and found that higher testosterone levels in boys in fact correlated with weaker social skills and narrower interests.

${ }^{48}$ There is much speculation that researchers will some day be able to show that these correlations are causal, that is, that fetal development spurred by the presence or absence of testosterone and other hormones affects the development of mirror neurons and their associated receptors, which in turn determines the level of individual social skills. See, e.g., Brizendine's speculation that women have more receptors for mirror neurons and the Scientific American suggestions that autism is related to a deficit in mirror neuron function. At this stage, however, scientists cannot prove with certainly what function mirror neurons serve with respect to complex behavior, much less that these correlations in fact determine gender differences or autism.

${ }^{49}$ Steven Pinker's summary of six primary areas of difference emphasizes preferences more than capacities: First, men and women generally differ with respect to their priorities, with men more likely to choose status rather than their families, and women being more balanced. Second, men and women show different vocational interests, with women more likely to choose to work with people, and men with things. Third, men are more likely to take risks. Fourth, men are better at three-dimensional mental rotation and perception. Fifth, while women are better at mathematical calculations, men are better at math-based work problems. Finally, men show more difference in variability than do women.
} 
Ramachandran, 2001). ${ }^{50}$ Men and women, of course, both have mirror neurons, and even if they involve different levels of sensitivity, they permit a theory of mind for both sexes. In addition, as performance across repeated iterations of the various modeling games indicates, both men and women are capable of altering their behavior in response to the reactions they receive from others. Just as we have come back to Gilligan, nature and nurture are increasingly coming together in a more comprehensive explanation of the feedback loops that nature provides to guide the social construction of human behavior $\left(\right.$ Spelke, 2005). ${ }^{51}$

\section{CONCLUSION}

In this article, we have attempted to identify the importance of gender for what we predict will be a new, progressive research agenda. We believe that both law and economics have shifted their focus from the obstacles to freedom and markets to the necessary attributes of a well functioning society. Behavioral economics, which has multiplied the exceptions to the rational actor model, and institutional economics, which has increasingly sought to understand the creation and function of collective entities, have underscored the limitations of neo-classical economics as an imperial discipline. As the research agenda has changed from identification of the reasons why state interventions have failed to determination of the institutions, private or public, that work,

\footnotetext{
50 . S. Ramachandran speculates, for example, that: "The discovery of mirror neurons in the frontal lobes of monkeys, and their potential relevance to human brain evolution . . . is the single most important "unreported" (or at least, unpublicized) story of the decade. I predict that mirror neurons will do for psychology what DNA did for biology: they will provide a unifying framework and help explain a host of mental abilities that have hitherto remained mysterious and inaccessible to experiments."

${ }^{51}$ Indeed, Janet Shibley Hyde suggests that studies should be interpreted through a "gender similarities" rather than a gender difference model. According to her meta-analysis, most studies have found only minimal differences. Where there are differences, the largest ones appear in studies of motor coordination, such as distance in throwing a ball, sexuality measures, such as masturbation and attitudes towards sex outside of committed relationships, and aggression, with men more likely to exhibit physical aggression and women to exhibit verbal facility.
} 
attention has turned to trust, cooperation, cultural norms, social meaning and altruism. While articulation of a new paradigm has not yet occurred, we predict that a new model will differ from the rational actor model in that:

1. It will seek to explain not just individual decisions, but the coordination of behavior. While conventional economics considers equilibrium points that arise from competition, social stability is a more complex construct. As Kahan notes, the reciprocity model produces more than one equilibrium point, with the creation of a high trust society resulting from the production of shared norms, internalized through something more than the profit-oriented incentive effects that attend individual transactions.

2. It will focus on the preference shaping process, necessarily relaxing any assumption of exogenously determined choices and values. Examination of "virtuous cycles," after all, necessarily involves consideration of the feedback loops that motivate behavior.

3. It will be sensitive to the allocation of resources and entitlements. As the "endowment effect" suggests, the perceived fairness of a transaction may well depend on the extent to which it accords with the expectations that follow from such allocations, and the perceived legitimacy of the entitlements.

4. It will consider the degree to which legal rules empower or frustrate collective responses. The ability of more socially conscious druggists 
to develop norms that facilitate access may be more effective than formal distribution programs.

5. It will consider the balance between empowering innovation, potentially destabilizing existing hierarchies and creating new ones, and providing support for an ethic of care.

The most important new tools contributing to this research are likely to incorporate evolutionary analysis, behavioral genetics and neuroscience, and with these techniques will necessarily come renewed attention to gender. Attention to the biological basis of difference, gender or otherwise, carries undeniable risks. Indeed, growing research on stereotype threat suggests that there may be a biological component to the perception of and internalization of role expectations (see e.g. Steele, 1997, Steele and Aronson, 1995, Kang and Banaji, 2006, McGlone and Aronson, forthcoming). And Judith Harris's new research on peer influence, undeniably an environmental factor in development, has been interpreted in terms of the tendency of the species to take small differences (with gender differences among the most obvious to pubescent teens) and exaggerate them as the basis for specialization and exchange (see Harris, 1999, Ridley, 2003).

Despite these risks, we believe that the reexamination of the biological bases of gender differences is inevitable, and that it offers more opportunities than risks for a progressive agenda. First, as the growing gender literature attests, the research is likely to be done whether or not feminists participate. Second, as developments in biology indicate, the research agenda itself changes when women participate (Hrydy, 1999). 
Third, as the research focus changes from self-interested behavior to cooperative behavior, so too do the opportunities for more progressive policies.

We have argued in this article that as the scholarly paradigm across the social sciences shifts to place greater emphasis on trust and reciprocity, the issue of gender has been notable largely to the degree to which it has relegated to the margins of the new discourse. There is, however, at least one remarkable exception. In 2001, the World Bank issued policy research report, "Engendering Development - Through Gender Equality in Rights, Resources, and Voice," which focused the broad economic and social implications of gender issues in developing and transitional countries (World Bank Report, see Stotsky 2006). ${ }^{52}$ The report found a correlation between the rights of women and the countries' economic and social well-being, and concluded that granting women more equal decision-making power produced benefits for the society as a whole. In reaching these conclusions, the report focused on two areas that illustrate the potential of the new thinking and contain suggestions for a broader research agenda.

First, the report seconds the conclusion that might be expected from an evolutionary account. In examining the allocation of resources at the household level, the study finds that

$\ldots[\mathrm{H}]$ ousehold resources are allocated in the face of competing preferences and unequal bargaining power among members. This conflicts with the traditional view of economists and policymakers that household members pool their resources and allocate them according to a unified set of preferences. One implication is that the distribution of resources within a household, not just the

\footnotetext{
${ }^{52}$ Available at The World Bank, http://wwwwds.worldbank.org/external/default/main?pagePK $=64193027 \& \mathrm{piPK}=64187937 \&$ theSitePK=523679\&men $\underline{\mathrm{uPK}}=64187510 \&$ searchMenuPK $=64187283 \&$ siteName=WDS\&entityID $=000094946 \_01020805393496$, last visited Nov. 20, 2006
} 
level of resources, matters. Policies that alter the distribution of resources among household members shift the balance of power among those members, with implications for gender equality and family welfare (World Bank Report,2001). ${ }^{53}$

At a practical level, what this means is that women are more likely to spend additional resources on their children while men are more likely to spend them on status enhancing purchases - including cars, alcohol and mistresses. The World Bank reports that "[a] growing body of evidence indicates that more resources in the hands of women mean greater household allocations to children. .... In Brazil additional income in the hands of mothers is associated with substantially larger improvements in child survival and nutrition than additional income in the hands of fathers. For child survival the marginal effect of female income is nearly 20 times larger than that of male income. And for child nutrition, the effect is four to eight times larger" (World Bank Report). The research further correlates child vaccination rates with the mother's educational levels. These studies emphasize that the allocation of power within families matter for reasons that lay the foundation for the well-being of the next generation. Although feminists have sought to separate issues involving women from those involving children, it is clear that in matters as disparate as the financial status of women post-divorce and the subsistence levels of women in the developing world, a focus on women benefits those for whom women provide care.

Second, the World Bank concludes that greater gender equality correlates with better governance and less corruption. The empirical studies on which the report relied find that higher representation of women in the legislature went together with lower

\footnotetext{
${ }^{53}$ Available at http://wwwwds.worldbank.org/external/default/WDSContentServer/WDSP/IB/2001/03/01/000094946_010208053934 96/Rendered/PDF/multi_page.pdf
} 
levels of corruption (Dollar et. al. 1999). The more intriguing issue is why. The study begins by observing how little research has been done on the role of gender in governance. It cites work done during the nineties suggesting that women may be less "selfish" than the stereotypical rational man, score higher on measures of ethics and integrity, and react more generously in making economic decisions (Dollar et. al. 1999). While these studies remain controversial, the authors refer to the work of a Russian political scientist who argues that women "rarely succumb to authoritarian styles of behavior and prefer not to maintain the sort of expensive entourage which often accompanies high-placed (male) officials," and they speculate that "the presence of women in the higher echelons of the hierarchical structures exercises an extremely positive influence on the behavior of their male colleagues by restraining, disciplining and elevating the latters' behavior" (Dollar et. al. 1999).

The World Bank used this report to support greater gender equality as a tool in development. Of course, gender equality is an outcome that could be justified directly rather than instrumentally, and the comments, which rest on empirical research on correlations without persuasive evidence of causation, too easily lead to essentialist views about men and women. But the findings nonetheless complement the issues that arise from behavioral biology and suggest that the qualities associated with the stereotypically masculine and feminine, if not always men and women, may play important roles in the well-being of society.

This approach represents a fundamental departure from the rational actor model as it considers the operation of the group rather than individual transactions, the differing contribution based on gender to collective well-being, the effect of initial entitlements on 
long term results, the creation of feedback loops that spur virtuous as opposed to vicious cycles, and the role of law in encouraging the process (see Cahn 2006, see generally Dallas 2003). ${ }^{54}$ And - as Gilligan might suggest - it acknowledges the importance of the balance between the masculine and the feminine in producing these results, finding value in emphasizing what women contribute.

We believe that to realize the potential a new paradigm will require revisiting the issue of feminism and, as the World Bank example illustrates, it will require reconsidering two issues. The most fundamental is the relationship between stereotypically masculine and feminine preferences. The former, associated with men but certainly not characterizing all men, involve the tendency to establish hierarchies, challenge the existing order when it enhances status to do so, prizes innovation and risktaking, and resorts more readily to violence. In contrast, the stereotypically feminine devotes greater attention to relational concerns, places a greater premium on inclusion and equality, is more attentive to interpersonal transactions, and contributes more to stability and productivity. We believe that all successful institutions, the military notably among them, carefully balance the tensions among these traits, whatever the identity of individuals who constitute them.

In addition, for society more generally, the relationship between the masculine and feminine requires attention to the connections between home and family. Postindustrial societies are undergoing a major redefinition of family life as fertility rates fall, relationships become more fragile, and women join men in the paid workforce

\footnotetext{
${ }^{54}$ Indeed, we would view the two obvious legal issues arising from this type of analysis as polygamy, where a long literature addresses the role of the family (and monogamy) in the creation of democracy, and corporate governance, where constraint of risk-taking, deception and fraud are important regulatory objectives.
} 
accelerating the changing boundaries between public and private, commercial and domestic. The role of family nonetheless remains important in the transmission of culture, values, and norms between generations, and in providing the primary emotional bonds that connect individuals to a sense of community.

Both of these dimensions are critical to understanding the creation of cooperation and trust in complex societies. And both issues are critical to the creation of a comprehensive new paradigm. After all, at this point in the life of the academy, the question of whether or not Heinz will (or should) steal the drug is not particularly interesting. ${ }^{55}$ The far more interesting questions are Amy's: why didn't the druggist sell to Heinz in the first place: greed, institutional or personal indifference, or a market based rationing system? And what is the legal system to make of the theft? We suspect that Amy might be a fraction of a second quicker than Jake to guess that if Heinz were black and the druggist white, the result of a conviction might be a riot; while if Heinz's theft caused the death of a sicker patient higher up on the rationing list, even Heinz's wife might condemn him. The construction of social trust, or norms, has replaced the abstract articulation of moral justifications as the more important question of the day.

\footnotetext{
${ }^{55}$ Indeed, the far more interesting question may be the circumstances in which our hypothetical Heinz might not steal the drug.
} 